\title{
PREDIÇÃO DOS FRACIONAMENTOS DE PROTEÍNAS DE BRACHIARIA BRIZANTHA CV MARANDU UTILIZANDO RNA
}

\author{
PREDICTION OF PROTEIN FRACTIONING OF BRACHIARIA BRIZANTHA CV MARANDU \\ THROUGH ARTIFICIAL NEURAL NETWORKS
}

\author{
Brennecke, K. ${ }^{1}$, Tech, A.R.B. ${ }^{2 *}$, Arce, A.I.C. ${ }^{2 A}$, Luz, P.H.C. ${ }^{2 B}$, Herling, V.R. ${ }^{2 C}$ e Costa, E.J.X. ${ }^{2 D}$ \\ ${ }^{1}$ Mestrado Stricto-Senso em Produção Animal. UNICASTELO Campus Descalvado. São Paulo. Brasil. \\ katheryb@usp.br \\ 2ZAB-FZEA. University of São Paulo. Pirassununga, SP. Brazil. *adriano.tech@usp.br, Aacaid@usp.br, \\ Bphcerluz@usp.br, cvrherlin@usp.br, Dernane@usp.br
}

\author{
PALAVRAS CHAVE ADICIONAIS \\ Forragicultura.
}

\section{RESUMO}

Este artigo tem como objetivo relacionar variáveis morfogenéticas da forragem e dados climáticos com as frações de proteínas (A, B1, B2, $\mathrm{B} 3$ e $\mathrm{C}$ ), através da rede neural aritifical conhecida como Multi-Layer Perceptron, com três camadas e algoritmo de treinamento baseado na retropropagação do gradiente do erro, a fim de criar um modelo capaz de predizer as frações protéicas de forragens a partir de suas características morfogenéticas e climáticas. Os dados utilizados para o treinamento e teste da rede foram coletados em um experimento que foi realizado em uma área experimental de 25,2 ha, com coordenadas $47^{\circ} 26^{\prime}$ W, $21^{\circ} 59^{\prime} \mathrm{S}$, formada com capim braquiarão, em um delineamento em blocos completos e casualizados, com 4 repetições e uma oferta de forragem de $5 \%$ ( $5 \mathrm{~kg}$ de massa seca por $100 \mathrm{~kg}$ de peso animal.dia-1). Cada bloco foi dividido em quatro unidades experimentais de 1,575 ha, com cinco piquetes de 0,315 ha cada. As amostras foram colhidas dois dias antes da entrada dos animais, sendo a análise das frações de proteínas realizadas em laboratório para posteriormente serem comparadas com os valores estimados pela rede. Assim, através da comparação entre os dados de saída da rede e os obtidos pela análise laboratorial foi possível calcular o erro médio para as frações A, B1, B2, B3 e C de proteínas e com isso, pode-se concluir que o modelo MLP é capaz de predizer com eficiência as frações de proteínas de Brachiaria brizantha.

Recibido: 2-3-10. Aceptado: 13-4-11.

\section{Additional KeYWORDS}

Forage.

\section{SUMMARY}

This paper aims to connect morphogenetic variables of forage and climatic data, with protein fractions (A, B1, B2, B3 and C) through the artificial neural networks known as Multi-Layer Perceptron, with three layers and algorithm training based on back-propagation of error gradient, in order to create a model to predict the protein fractions of fodder from their morphogenetic characteristics and climate. The data used for training and the test were collected in an experiment that was conducted on a 25.2 ha experimental area, located at $47^{\circ} 26^{\prime} \mathrm{W}$, $21^{\circ} 59^{\prime} \mathrm{S}$, and with pasture composed of Brachiaria brizantha cv Marandu, in a completely randomized block, with four replicates and a forage allowance of $5 \%$ ( $5 \mathrm{~kg}$ of dry matter per $100 \mathrm{~kg}$ animal.day ${ }^{-1}$ ). Each block was divided into four experimental units of 1.575 ha, with five paddocks of 0.315 ha each. Samples were taken two days before the entry of animals, protein was analysed at laboratory to subsequently be compared with the values estimated by the network. Thus, by comparing the output of the network and those obtained by laboratory analysis, it was possible to calculate the average error for fractions A, B1, B2, B3 and $C$ proteins and, thus, can be concluded that the model MLP is able to efficiently predict protein fractions of Brachiaria brizantha.

\section{INTRODUÇÃO}

O uso de técnicas avançadas de proce-

Arch. Zootec. 60 (232): 1271-1279. 2011. 
ssamento digital de sinais, principalmente o uso de modelos, baseados em redes neurais artificiais, permite inferir relações existentes entre variáveis do meio ambiente e características qualitativas de plantas. Possibilitando assim, a avaliação antecipada das características morfofisiológicas e químicas das plantas em função das condições ambientais em menor de tempo e com menor custo de análise.

O sistema de funcionamento do neurônio biológico (Rumelhart et al., 1986) é a base da rede neural artificial (RNA) que pode ser definida como um conjunto de neurônios artificiais capazes de processar informações.

As redes multi-layer percetron são um tipo de redes neurais que tem a habilidade de identificar padrões ou características após um treinamento. Essa estrutura de aprendizagem está ligada a um algoritmo de aprendizagem que é utilizado para treinar a rede e gerar informações sobre determinados eventos. Ela é formada basicamente por uma camada de neurônios de entrada, um ou mais camadas escondidas e uma camada de saída, responsável por gerar a saída da rede (Hertzetal., 1991).

Há estudos que mostram a viabilidade da RNA em programas agronômicos e zootécnicos, mostrando a capacidade das RNA's de mapear relações complexas entre variáveis ambientais e características intrínsecas das plantas e animais. Como exemplos da aplicação de RNAs na modelagem de ambientes de ambientes biológicos podem-se citar o estudo de Elizondo et al. (1994) que utilizaram uma RNA para predizer o florescimento e a maturidade fisiológica em soja, onde usaram trinta e três campos experimentais durante cinco anos; Edwards e Coob (1997) que estudaram o efeito da temperatura no acúmulo de clorofila e glicoalcalóide em batatas (Solanun tuberosum L. cv King Edward), armazenadas em $5,10,20$ e $25^{\circ} \mathrm{C}$ por 8 dias, em baixa densidade de fluxo de fóton, incluindo um modelo preliminar usando uma RNA; Parmar et al. (1997) estimaram a contami- nação de aflatoxina em amendoim usando RNA, e concluíram que a RNA tem melhor performance que as técnicas tradicionais. Tambén, Yang et al. (1997a), ao utilizarem a RNA para avaliar as concentrações de pesticida no solo e Yang et al. (1997b) aplicaram RNA para simular temperatura de solos; Zee (2003), trabalhando com o programa NASA's Advance Life Support, utilizou redes neurais artificiais para caracterizar o processo de fotossíntese em soja.

Estes trabalhos mostram que a capacidade de predição e análise das RNAs em sistemas, onde as relações entre o clima $\mathrm{X}$ planta $\mathrm{x}$ animal associadas ao seu manejo, são complexas e todos os modelos comprovaram a viabilidade do emprego das RNAs.

Uma vez que a qualidade nutricional de uma forrageira está, entre outros fatores de ordem nutricionais, relacionada as frações da proteína, surge a seguinte questão: Pode se estimar essas frações de proteínas a partir de uma correlação das condições ambientais e morfofisiológicas da forrageira, a campo?

Nos ecossistemas de pastagens existe uma interação complexa entre os componentes solo-planta-animal. Portanto, o desenvolvimento, o crescimento e a senescência de folhas e perfilhos constituem processos fisiológicos que determinam mudanças significativas nos ecossistemas. Crescimento e desenvolvimento são processos distintos, porém correlacionados (Nascimento Júnior et al., 2002).

As análises desses parâmetros constituem importante ferramenta, tanto para a caracterização do potencial de produção da espécie como para a definição do potencial de uso de dado ecossistema na produção animal. Tão importante quanto saber qual será a produção é saber como esta produção está distribuída no tempo e espaço. Deste modo, a interação da planta com o meio ambiente constitui-se de fundamental importância para suportar, tanto o crescimento quanto a manutenção da capacidade produtiva da pastagem e com isso garantir 
um produto final de qualidade para o animal.

Em relação ao fracionamento de proteínas, o grande mérito desse sistema é caracterizar quimicamente os alimentos de forma compatível aos processos de fermentação ruminal e digestão pós-ruminal, de forma que torna possível a utilização de modelos dinâmicos a partir dos quais o desempenho animal pode ser predito, no entanto, não estabelecem diretamente as relações entre as variáveis do ambiente, as características morfológicas e fisiológicas e a qualidade nutricional, que são consideradas, em geral, complexas, necessitando assim, serem analisadas em laboratórios.

Diante disso, uma resposta a essa questão é adequar a interação à produção quantitativa e qualitativa da planta forrageira e para isso pode se usar uma ferramenta que permita uma forma de predizer as condições nutricionais da planta forrageira, ainda no campo, com a utilização de dados históricos, da planta, previamente obtidos, sem a necessidade de avaliações laboratoriais, a fim de facilitar a aquisição de dados qualitativos de pastagens e aprimoramento de manejo, além de reduzir o tempo de análises e custos.

Portanto, o propósito deste trabalho foi o de investigar a eficiência de utilização de um modelo de redes neurais do tipo MLP (Multilayer Perceptron) com o objetivo de predizer os fracionamentos de proteínas de Brachiaria brizantha cv Marandu.

\section{MATERIALE MÉTODOS}

\section{ÁREAdOESTUdO}

O experimento foi conduzido em área pertencente à Faculdade de Zootecnia e Engenharia de Alimentos FZEA/USP, Pirassununga/SP, no período de janeiro a julho de 2004. A posição geográfica é 21 ${ }^{\circ} 59^{\prime}$ de latitude sul e $47^{\circ} 26^{\prime}$ de longitude oeste, com uma altitude de 634 metros, sendo o clima subtropical do tipo Cwa (Köppen e Geiger, 1928), com inverno seco e verão quente e chuvoso.

\section{DelineAmENTO EXPERIMENTAL}

A área formada com capim braquiarão foi dividida em 80 piquetes de 0,315 ha e posteriormente foi realizada a análise química do solo, para efeito de correção do solo.

O experimento constou de 4 ciclos de pastejo com duração de 28 dias cada, isto é, os animais ficavam durante um período total de 28 dias para completar o tempo de pastejo na área; em cada área haviam quatro unidades onde os animais ficavam durante sete dias, e o manejo dos animais estabelecido foi o método rotacionado, sendo o período de ocupação de 7 dias. Os tratamentos experimentais foram representados pela oferta de forragem a $5 \%(\mathrm{~kg} \mathrm{MS} / 100 \mathrm{~kg}$ de peso animal/dia), O delineamento experimental utilizado foi em blocos completos e casualizados com quatro repetições. Cada bloco foi dividido em quatro unidades experimentais de $1,575 \mathrm{ha}$, com cinco piquetes de 0,315 ha cada. As amostras da forragem para as análises laboratoriais foram colhidas dois dias antes da entrada dos animais, à altura do resíduo do pastejo anterior.

No período do experimento, foram realizadas análises morfofisiológicas da pastagem. As amostras de forragem colhidas foram embaladas em sacos de polietileno, identificadas e enviadas ao laboratório para pesagem da matéria original. No laboratório, essas amostras foram levadas a estufa de circulação forçada a temperatura de $55^{\circ} \mathrm{C}$, até que se atingisse uma massa constante, armazenadas para posteriores análises.

As frações protéicas foram obtidas conforme método descrito por Licitra et al. (1996) e foi realizada uma estatística básica para verificação da média dos resultados e do desvio padrão para cada ciclo de pastejo. Esses resultados serviram como valores de alimentação do banco de conhecimento, no caso os ajustes dos pesos sinápticos da rede neural, na fase de treino.

\section{Rede neural ARTIFICIAL}

O software foi desenvolvido utilizando 
a linguagem de programação orientada a objetos $\mathrm{C}++$.

Os experimentos computacionais foram feitos em três etapas:

1) Preparação e digitalização dos dados obtidos pelo fracionamento de proteínas e os demais dados de ambiente;

2) Treinamento da RNA e;

3) Teste e validação da RNA.

Os dados que compuseram a etapa de preparação e digitalização foram:

$A$-Dados fixos: latitude, longitude, ciclos de pastejo (fevereiro a julho - 1 ao 4), oferta de forragens $(5,10,15$ e $20 \%)$ e unidades experimentais (1 ao 16).

$B$-Dados variáveis (morfofisiológicos): média da altura pré pastejo, média da altura pós pastejo, diferenças entre as alturas pré e pós pastejo, perfilhos decapitados, perfilhos remanescentes, perfilhos novos, perfilhos aéreos remanescentes, perfilhos aéreos novos, perfilhos resprodutivos, perdas no solo, perdas na planta, perdas total, produção de massa (kg/ha) pré pastejo, produção de massa $(\mathrm{kg} / \mathrm{ha})$, pós pastejo, densidade da folha pré pastejo $(<15,15-30$, $30-45,>45 \mathrm{~cm})$, densidade da folha pós pastejo $(<15,15-30,30-45,>45 \mathrm{~cm})$, densidade total pré pastejo $(<15,15-30,30-45,>45$ $\mathrm{cm})$, densidade total pós pastejo $(<15,15$ $30,30-45,>45 \mathrm{~cm})$, estratificação pré pastejo folha verde $(<15,15-30,30-45,>45 \mathrm{~cm})$, estratificação pré pastejo colmo + bainha $(<15,15-30,30-45,>45 \mathrm{~cm})$, estratificação pré pastejo senescência $(<15,15-30,30-45$, $>45 \mathrm{~cm}$ ), estratificação pós pastejo folha verde $(<15,15-30,30-45,>45 \mathrm{~cm})$, estratificação pós pastejo colmo + bainha $(<15$, $15-30,30-45,>45 \mathrm{~cm})$, estratificação pós pastejo senescência $(<15,15-30,30-45,>45$
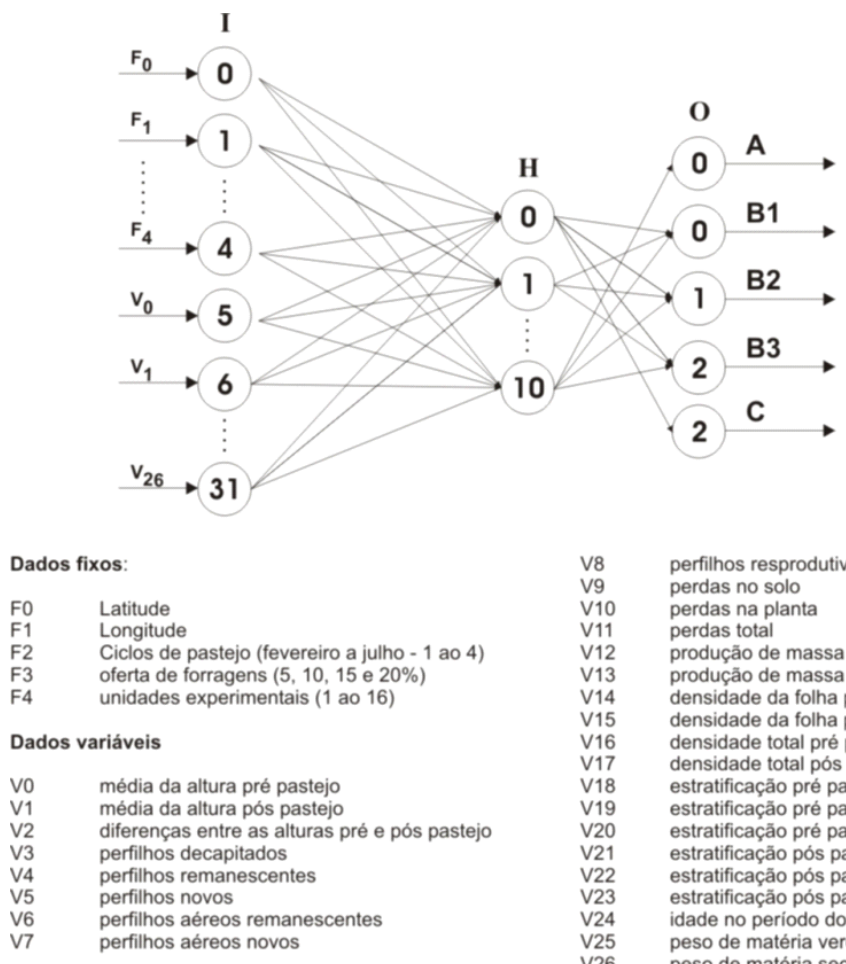

perfilhos resprodutivos

perdas no solo

perdas na planta

perdas total

produção de massa $(\mathrm{kg} / \mathrm{ha})$ pré pastejo

produçāo de massa $(\mathrm{kg} / \mathrm{ha}$ ) pós pastejo

densidade da folha pré pastejo $(<15,15-30,30-45,>45 \mathrm{~cm})$ densidade da folha pós pastejo $(<15,15-30,30-45,>45 \mathrm{~cm})$ densidade total pré pastejo $(<15,15-30,30-45,>45 \mathrm{~cm})$ densidade total pos pastejo $(<15,15-30,30-45,>45 \mathrm{~cm})$ estratificação pré pastejo folha verde $(<15,15-30,30-45,>45 \mathrm{~cm})$ estratificação pré pastejo colmo + bainha $(<15,15-30,30-45,>45 \mathrm{~cm})$ estratificçção pré pastejo senescência (<15, 15-30,30-45, >45 cm) estratificação pós pastejo folha verde $(<15,15-30,30-45,>45 \mathrm{~cm})$ estratificação pós pastejo colmo + bainha $(<15,15-30,30-45,>45 \mathrm{~cm})$ estratificação pós pastejo senescência $(<15,15-30,30-45,>45 \mathrm{~cm})$ idade no periodo do experimento

peso de matéria verde em função da simulação de pastejo

peso de matéria seca em função da simulação de pastejo.

Figura 1. Modelo da rede multi-layer perceptron. (Model of network multi-layer perceptron). 
$\mathrm{cm})$, idade no período do experimento, peso de matéria verde em função da simulação de pastejo, peso de matéria seca em função da simulação de pastejo.

C-Dados variáveis (químicos): frações de proteínas (fração A, B1, B2, B3 e C).

Para isso, a rede constou de 32 camadas de entrada, 11 camadas escondidas e 5 camadas de saída, onde a camada de entrada foi composta pelas variáveis morfofisiológicas juntamente com os dados fixos. A camada de saída foi composta pelas 5 frações de proteínas (dados químicos).

Para o treinamento da rede MLP foram utilizados $2 / 3$ dos dados.

$\mathrm{O}$ modelo de rede utilizado por ser visualizado através da figura 1.

A figura 1 ilustra os elementos de entrada da rede, onde foram utilizados dados variáveis e dados fixos, sendo a saída da mesma representada pelas respectivas respostas, A, B1, B2, B3 e C.

Na etapa de teste e validação da RNA foi

Tabela I. Modelo da matriz de confusão utilizada nos experimento. (Confusion matrix model used in the experiment).

\begin{tabular}{llllllllll}
\hline \multicolumn{10}{c}{ Fração X } \\
CP & & R & erro & R & erro & R & erro & R erro \\
\hline 1 & $\mathrm{~L}$ & $\mathrm{n}$ & $\mathrm{e}$ & - & - & - & - & - & - \\
1 & $\mathrm{~L}$ & $\mathrm{n}$ & - & - & - & - & - & - & - \\
1 & $\mathrm{~L}^{*}$ & $\mathrm{n}$ & - & - & - & - & - & - & - \\
1 & $\mathrm{~L}$ & $\mathrm{n}$ & - & - & - & - & - & - & - \\
2 & $\mathrm{~L}$ & - & - & $\mathrm{n}$ & $\mathrm{e}$ & - & - & - & - \\
$\ldots$ & $\mathrm{L}^{*}$ & - & - & $\mathrm{n}$ & - & - & - & - & -
\end{tabular}

CP: ciclos de pastejo (do 1 ao 4 com 4 repetições cada); L: média dos resultados do fracionamento obtidos em laboratório; R: valor exato encontrado pela RNA; n: valor obtido entre as diferenças dos resultados da RNA e do laboratório; Erro: erro padrão dos resultados obtidos pela RNA em função dos resultados obtidos em laboratório; e: valor do erro padrão.

*valor em negrito= valor aleatoriamente escolhido para ser o teste da RNA. utilizado o $1 / 3$ restante da base de dados. Foram processados pela rede já treinada todos os valores das variáveis analisadas, e foram obtidas as estimativas de fracionamento de proteínas (A, B1, B2, B3 e C). Os valores de todas as variáveis de entrada foram dispostos na rede através de médias.

A validação estatística da RNA foi efetuada segundo o método de matriz de confusão ou método Kapa (Vuolo, 1996), conforme verificado na tabela I, para cada uma das frações de proteínas. Essas matrizes de confusão foram desenvolvidas a partir da média dos resultados obtidos em laboratório (demonstrados pelos valores da coluna) com os valores absolutos obtidos na RNA (demonstrados pelos valores da linha), conforme exemplificado na figura 1. Os valores atribuídos para o teste da rede foram aleatórios e estão marcados em negrito na tabela $\mathbf{I}$.

\section{RESULTADOSEDISCUSSÕES}

Os resultados obtidos nesse experimento são composições dos resultados laboratoriais e comparados com os valores obtidos pela RNA.

$\mathrm{O}$ resultado da fração $\mathrm{A}$, bem como a matriz de erro podem ser observados na tabela II. A fração A é composta de aminoácidos, peptídeos e nitrogênio não protéico, sendo de disponibilidade imediata no rúmen. Essa fração depende diretamente do teor de proteína bruta, e isso irá depender da idade da planta, bem como do manejo adotado. Como um elemento biológico, cada planta irá possuir um valor de proteína e conseqüentemente de frações de proteínas. Diante disso, uma maneira de aproximar os valores obtidos em laboratório é compondo a média das amostras e seu desvio padrão.

No caso do presente experimento, os valores da fração A de proteína obtidos em laboratório tiveram um desvio padrão médio de 0,$05 ; 0,13 ; 0,13$ e 0,06 .

A RNA tem como resultado um único valor absoluto, porém, vindo de dados 
Tabela II. Resultados da fração A obtidos em laboratório e na RNA. Matriz de erro: fração $A$ de proteina bruta. (The results of the fraction A obtained in the laboratory and in the RNA. Error matrix: fraction $A$ of the crude protein).

Fração A (\%)

CP 0,43 erro 0,43 erro 0,48 erro 0,43 erro

\begin{tabular}{llllllllll}
\hline & 0,43 & 0,00 & 0,05 & - & - & - & - & - & - \\
1 & 0,33 & 0,10 & - & - & - & - & - & - & - \\
1 & 0,45 & $-0,02$ & - & - & - & - & - & - & - \\
1 & 0,43 & 0,00 & - & - & - & - & - & - & - \\
2 & 0,53 & - & - & $-0,10$ & 0,13 & - & - & - & - \\
2 & 0,46 & - & - & $-0,03$ & - & - & - & - & - \\
2 & 0,67 & - & - & $-0,24$ & - & - & - & - & - \\
2 & 0,51 & - & - & $-0,07$ & - & - & - & - & - \\
3 & 0,54 & - & - & - & - & $-0,06$ & 0,14 & - & - \\
3 & 0,53 & - & - & - & - & $-0,05$ & - & - & - \\
3 & 0,75 & - & - & - & - & $-0,27$ & - & - & - \\
3 & 0,45 & - & - & - & - & 0,03 & - & - & - \\
4 & 0,33 & - & - & - & - & - & - & 0,11 & 0,06 \\
4 & 0,45 & - & - & - & - & - & - & $-0,01$ & \\
4 & 0,42 & - & - & - & - & - & - & 0,02 & \\
4 & 0,32 & - & - & - & - & - & - & 0,06 & \\
\hline
\end{tabular}

inseridos no seu treinamento. Esses dados foram coletados do sistema solo x planta ao longo do experimento.

Pode-se observar que, considerando os erros, estatisticamente, os valores médios obtidos em laboratório e o valor encontrado pela RNA, são iguais.

A tabela III mostra a média dos resultados dos valores da fração B1 de proteína no laboratório, os valores encontrados pela rede e a matriz de erro.

A subdivisão da fração B (B1, B2 e B3) é baseada nas taxas de degradação, no rumem, de cada fração.

Em laboratório a fração B1 é obtida pela diferença entre a proteína solúvel menos a fração A (B1= PS - A), correspondendo a proteína verdadeira solúvel em solução tampão.

A taxa de degradação desta fração é muito superior à taxa de pesagem da dieta no rumem, sendo totalmente degradada. Em silagens, a fração B1 corresponde à porção muito pequena da proteína solúvel (por volta de 5\%), porém, em forragens verdes, a maior parte da proteína solúvel é proteína verdadeira (B1).

Pode-se observar diante dos resultados obtidos que a RNA conseguiu predizer os valores da fração B1, onde o erro foi menor que o desvio padrão encontrado no laboratório, que foi de 0,$04 ; 0,07 ; 0,06$ e 0,04 para os ciclos de pastejos 1, 2, 3 e 4 .

Os resultados e a matriz de erro da fração B2 podem ser observados na tabela IV.

A fração B2 é calculada subtraindo-se da proteína bruta a proteína solúvel (frações A e B1), a fração B3 e a fração C são calculadas através da fórmula: $\mathrm{B} 2=[\mathrm{PB}-(\mathrm{A}+\mathrm{B} 1$ $+\mathrm{B} 3+\mathrm{C})]$.

A taxa de degradação da fração B2 é semelhante à taxa de pesagem, de forma que a quantidade efetivamente degradada no rúmen é função direta da taxa de pesagem,

Tabela III. Resultados da fração B1 obtidos em laboratório e na RNA. Matriz de erro: fração B1 de proteina bruta. (The results of the fraction B1 obtained in the laboratory and in the RNA. Error matrix: fraction B1 of the crude protein).

Fração B1

CP 0,12 erro 0,14 erro 0,02 erro 0,17 erro

\begin{tabular}{llllllllll}
1 & 0,12 & 0,00 & 0,03 & - & - & - & - & - & - \\
1 & 0,15 & $-0,03$ & - & - & - & - & - & - & - \\
1 & 0,11 & 0,01 & - & - & - & - & - & - & - \\
1 & 0,06 & 0,06 & - & - & - & - & - & - & - \\
2 & 0,18 & - & - & $-0,04$ & 0,07 & - & - & - & - \\
2 & 0,14 & - & - & 0,00 & - & - & - & - & - \\
2 & 0,01 & - & - & 0,13 & - & - & - & - & - \\
2 & 0,10 & - & - & 0,04 & - & - & - & - & - \\
3 & 0,07 & - & - & - & - & $-0,05$ & 0,07 & - & - \\
3 & 0,08 & - & - & - & - & $-0,06$ & - & - & - \\
3 & 0,02 & - & - & - & - & 0,00 & - & - & - \\
3 & 0,15 & - & - & - & - & $-0,14$ & - & - & - \\
4 & 0,25 & - & - & - & - & - & - & $-0,08$ & 0,04 \\
4 & 0,18 & - & - & - & - & - & - & $-0,01$ & - \\
4 & 0,16 & - & - & - & - & - & - & 0,01 & - \\
4 & 0,18 & - & - & - & - & - & - & $-0,01$ & - \\
\hline
\end{tabular}


Tabela IV. Resultados da fração B2 obtidos em laboratório e na RNA. Matriz de erro: fração $B 2$ de proteína bruta. (The results of the fraction B2 obtained in the laboratory and in the RNA. Error matrix: fraction B2 of the crude protein).

\begin{tabular}{|c|c|c|c|c|c|c|c|c|}
\hline \multirow{2}{*}{$\frac{C P}{10,213}$} & \multicolumn{8}{|c|}{$\begin{array}{c}\text { Fração B2 } \\
0,166 \text { erro } 0,315 \text { erro0,381 erro0 }\end{array}$} \\
\hline & $-0,05$ & 0,11 & - & - & - & - & - & - \\
\hline 10,292 & $-0,13$ & - & - & - & - & - & - & - \\
\hline 10,255 & $-0,09$ & - & - & - & - & - & - & - \\
\hline 10,310 & $-0,14$ & - & - & - & - & - & - & - \\
\hline 20,152 & - & - & 0,16 & 0,11 & $1-$ & - & - & - \\
\hline 20,254 & - & - & 0,06 & - & - & - & - & - \\
\hline 20,177 & - & - & 0,14 & - & - & - & - & - \\
\hline 20,263 & - & - & 0,05 & - & - & - & - & - \\
\hline 30,283 & - & - & - & - & 0,10 & 0,21 & $1 \quad-$ & - \\
\hline 30,297 & - & - & - & - & 0,08 & - & - & - \\
\hline 30,018 & - & - & - & - & 0,30 & - & - & - \\
\hline 30,232 & - & - & - & - & 0,15 & - & - & - \\
\hline 40,330 & - & - & - & - & - & & $-0,11$ & 0,06 \\
\hline $4 \quad \mathbf{0 , 2 3 0}$ & - & - & - & - & - & & $-0,01$ & - \\
\hline 40,220 & - & - & - & - & - & & 0,00 & - \\
\hline 40,190 & - & - & - & - & - & - & 0,03 & - \\
\hline
\end{tabular}

isto é, dependerá da relação entre taxa de degradação/taxa de passagem. Em alimentos cuja fração B2 é significativa, a correta avaliação destes parâmetros é fundamental à avaliação dos alimentos e das dietas.

O desvio padrão das frações B2 obtidas em laboratórios foram 0,$04 ; 0,05 ; 0,13$ e 0,06, valores aquém ao encontrado na matriz de erros, quando comparadas às médias dos valores obtidas em laboratório com o resultado da RNA, para a fração B2.

Como se pode observar a fração B2 é considerada como um resíduo e obtida por cálculo matemático, portanto, essa fração é completamente dependente dos resultados das demais frações da proteína, e a proteína, por sua vez, dependente dos processos biológicos do trinômio planta x solo x clima.

A fração B3 é determinada pela subtração entre o nitrogênio insolúvel em detergente neutro e o nitrogênio insolúvel em detergente ácido (B3= NIDN - NIDA), sendo caracterizada pela lenta degradação no rúmen, uma vez que está associada à parede celular.

Os suplementos protéicos contêm pequena quantidade de B3; porém, esta fração assume importância em forragens, grãos fermentados e subprodutos (Krishnamoorthy et al., 1983). Em função da reduzida taxa de degradação da fração B3, grande parte escapa à degradação ruminal, de acordo com o CNCPS.

Os resultados obtidos da fração B3 e a matriz de erro podem ser observados na tabela $V$.

Os resultados dos desvios padrão dos valores da fração B3 obtidas em laboratórios foram respectivamente para os cilos de pastejos $1,2,3$ e 4 de 0,$02 ; 0,01 ; 0,05$ e 0,01 .

$\mathrm{A}$ fração $\mathrm{C}$ corresponde à proteína indisponível, sendo insolúvel em detergente ácido, abreviado por NIDA (nitrogênio insolúvel em detergente ácido). Essa fração

Tabela $V$. Resultados da fração B3 obtidos em laboratório e na RNA. Matriz de erro: fração $B 3$ de proteína bruta. (The results of the fraction B3 obtained in the laboratory and in the RNA. Error matrix: fraction B3 of the crude protein).

Fração B3

CP $\quad 0,17$ erro 0,09 erro 0,12 erro 0,06 erro

\begin{tabular}{llllllllll}
\hline & 0,16 & 0,01 & 0,03 & - & - & - & - & - & - \\
1 & 0,18 & $-0,01$ & - & - & - & - & - & - & - \\
1 & 0,12 & 0,05 & - & - & - & - & - & - & - \\
1 & 0,15 & 0,02 & - & - & - & - & - & - & - \\
2 & 0,10 & - & - & $-0,01$ & 0,01 & - & - & - & - \\
2 & 0,10 & - & - & $-0,01$ & - & - & - & - & - \\
2 & 0,09 & - & - & 0,00 & - & - & - & - & - \\
2 & 0,08 & - & - & 0,01 & - & 0,04 & - & - & - \\
3 & 0,07 & - & - & - & - & 0,05 & 0,05 & - & - \\
3 & 0,06 & - & - & - & - & 0,06 & - & - & - \\
3 & 0,18 & - & - & - & - & $-0,06$ & - & - & - \\
3 & 0,10 & - & - & - & - & 0,02 & - & - & - \\
4 & 0,10 & - & - & - & - & - & - & $-0,04$ & 0,03 \\
4 & 0,08 & - & - & - & - & - & - & $-0,02$ & - \\
4 & 0,11 & - & - & - & - & - & - & $-0,05$ & - \\
4 & 0,09 & - & - & - & - & - & - & $-0,03$ & - \\
\hline
\end{tabular}


Tabela VI. Resultados da fração C obtidos em laboratório e na RNA. Matriz de erro: fração $C$ de proteína bruta. (The results of the fraction $\mathrm{C}$ obtained in the laboratory and in the RNA. Error matrix: fraction $\mathrm{C}$ of the crude protein).

Fração C

CP 0,05 erro 0,06 erro 0,05 erro 0,05 erro

\begin{tabular}{llllllllll}
\hline & 0,07 & $-0,02$ & 0,01 & - & - & - & - & - & - \\
1 & 0,05 & 0,00 & - & - & - & - & - & - & - \\
1 & 0,06 & $-0,01$ & - & - & - & - & - & - & - \\
1 & 0,05 & 0,00 & - & - & - & - & - & - & - \\
2 & 0,04 & - & - & 0,02 & 0,01 & - & - & - & - \\
2 & 0,05 & - & - & 0,01 & - & - & - & - & - \\
2 & 0,05 & - & - & 0,01 & - & - & - & - & - \\
2 & 0,05 & - & - & 0,01 & - & - & - & - & - \\
3 & 0,04 & - & - & - & - & 0,01 & 0,01 & - & - \\
3 & 0,03 & - & - & - & - & 0,02 & - & - & - \\
3 & 0,04 & - & - & - & - & 0,01 & - & - & - \\
3 & 0,07 & - & - & - & - & $-0,02$ & - & - & - \\
4 & 0,04 & - & - & - & - & - & - & 0,01 & 0,01 \\
4 & 0,05 & - & - & - & - & - & - & 0,00 & - \\
4 & 0,05 & - & - & - & - & - & - & 0,00 & - \\
4 & 0,06 & - & - & - & - & - & - & $-0,01$ & - \\
\hline
\end{tabular}

contém proteínas associadas à lignina, taninos e a compostos de Maillard altamente resistentes à degradação microbiana $\mathrm{e}$ enzimática, sendo considerada inaproveitável, tanto no rúmen como pós-ruminal (Sniffen et al., 1992). No entanto, sabe-se que o NIDA não é totalmente indigestível. Em forragens, os autores apontaram digestibilidade da ordem de $30 \%$, ao passo que em concentrados esta digestibilidade atingiu até $60 \%$.

A porcentagem resultante da fração $C$ constata a tendência de aumento da proporção indigerível da parede celular, constituída basicamente de lignina, com o avanço da idade da planta forrageira.

Os valores da fração $\mathrm{C}$ da proteína e a matriz de erro podem ser observados através da tabela VI. Os valores do desvio padrão obtidos nas análises de laboratório em função dos ciclos de pastejos foram 0,01 ;
0,$01 ; 0,01$ e 0,01 , esses valores são próximos aos erros obtidos quando comparados com o erro mostrado na matriz de erro.

Os resultados mostram que as predições realizadas pela rede MLP são semelhantes aos resultados obtidos pela análise laboratorial, ou seja, a rede MLP, após o treinamento efetuado, conseguiu determinar valores próximos aos encontrados em laboratório e com a margem de erro dentro do esperado.

As frações B2 e B3 são resultantes de cálculos matemáticos onde são excluídos os valores de determinados elementos nutricionais. Esses elementos nutricionais excluídos são dependentes do trinômio solo $\mathrm{x}$ planta $\mathrm{x}$ clima, que foram utilizados para compor a base de dados para o treinamento da rede, e nesse caso, a RNA não conseguiu prever com precisão os valores dessas frações, porém, tais valores eqüidistam da média dessas frações encontradas no laboratório.

\section{CONCLUSÕES}

O estudo permitiu verificar através dos testes que é possível realizar as predições referentes às frações $\mathrm{A}, \mathrm{B} 1, \mathrm{~B} 2, \mathrm{~B} 3 \mathrm{e} \mathrm{C}$ sem a necessidade de análises laboratoriais, diminuindo assim, o tempo de resposta e os custos operacionais das mesmas.

Observou-se que todos os teores das frações protéicas obtidas pela RNA, mesmo não estando dentro do erro esperado, estão dentro da variação encontrada em pesquisas com plantas forrageiras de clima tropical.

Conclui-se assim, que as redes neurais baseado no modelo MLP e com retropropagação de erros, consegue predizer com eficiência todas as frações de proteínas em relação às estimativas obtidas por análises laboratoriais, desde que alteradas os padrões que as relacionam nas frações que são determinadas basicamente por cálculos matemáticos excluindo elementos nutricionais. 
FRACIONAMENTOS DE PROTEÍNAS ATRAVÉS DAS REDES NEURAIS ARTIFICIAIS

\section{BIBLIOGRAFIA}

Edwards, E.J. and Cobb, A.H. 1997. Effect of temperature on glicoalkaloid and chlorophyll accumulation in potatoes (Solanum tuberosum L. cv King Edward) stored at low photon flux density, including preliminary modeling using an artificial neural network. Am. Chem. Soc., 45: 1032-1038.

Elizondo, D.A., McClendon R.W. and Hoogenboom G. 1994. Neural network models for predicting flowering and phisiological maturity of soybean. Amer. Soc. Agric. Eng., 37: 981-988.

Hertz, J., Krogh, A. and Palmer, R.G. 1991. Introduction to the theory of neural computation. Santa Fe Institute studies in the sciences of complexity. Computation and neural system series 1. $280 \mathrm{pp}$.

Köppen, W. and Geiger, R. 1928. Klimate der erde. Wall-map $150 \mathrm{~cm} \times 200 \mathrm{~cm}$. Justus Perthes Verlag. Gotha. 1928.

Krishnamoorthy, U., Sniffen, C.J. and Stern, M.D. 1983. Evaluation of a mathematical model of rumen digestion and an in vitro simulation of rumen proteolysis to estimate the rumenundegraded nitrogen content of feedstuffs. Brit. J. Nutr., 50: 555-568.

Licitra, G., Hernandez, T.M. and Van Soest, P.J. 1996. Nitrogen fraction in selected feedtuffs. $J$. Dairy Sci., 65: 217-225.

Nascimento Junior, D., Neto Garces, A. F., Barbosa, R.A. e Andrade, C.M. 2002. Fundamentos sobre manejo de pastagem: Evolução e atualidade. Simpósio sobre Manejo de Pastagem. Universi- dade Federal de Viçosa. Viçosa. pp. 149-187. Parmar, R.S., McClendon R.W., Hoogenboom, G., Blankenship, P.D., Cole, R.J. and Dorner, J.W. 1997. Estimation of aflatoxinin contamination in preharvest peanuts using neural networks. Amer. Soc. Agric. Eng., 40: 809-813.

Rumelhart, D.E., Hilton, G.E. and Willians, R.J. 1986. Learning representation by backpropagation errors. Nature, 323: 533-536.

Sniffen, C.J., O'connor, J.D. and Van Soest, P.J. 1992. A net carboydrate and protein system for evaluating cattle diets: II. Carbohydrate and protein availability. J. Anim. Sci., 70: 3562-3577.

Vuolo, J.H. 1996. Fundamentos da teoria dos erros. $2^{a}$ ed. Ed. Edigard Blücher Ltda. São Paulo, SP. 240 pp.

Yang, C.C., Prasher, S.O., Sreekanth, S., Patni, N.K. and Masse, L. 1997a. An artificial neural network model for simulating pesticide concentrations in soil. T. ASAE, 40: 1285-1294.

Yang, C.C., Prasher, S.O., Mehuys, G.R. and Patni, N.K. 1997b. Application of artificial neural networks for simulation of soil temperature. $T$. ASAE, 40: 649-656.

Zee, F. 2003. Modeling of assimilation and transpiration in soybean plants using artificial neural networks. Sponsored by NASA. Office of life and microgravity Sciences and Applications. Jet Propulsion Laboratory. California Institute of Technology. <http://trsnew.jpl.nasa.gov/dspace/bitstream/2014/ 16369/1/00-2368.pdf> (30/09/2009). 